\title{
Effects of water pulsing on individual performance and competitive hierarchies in plants
}

\author{
Novoplansky, Ariel ${ }^{1,2 *}$ \& Goldberg, Deborah E. ${ }^{1}$ \\ ${ }^{1}$ Department of Biology, University of Michigan, Ann Arbor, MI 48109, USA; ${ }^{2}$ Department of Desert Ecology, The Jacob \\ Blaustein Institute for Desert Research, Ben-Gurion University of the Negev, Midreshet Sede-Boker 84990, Israel; \\ "Corresponding author; Fax+97276596821; E-mail anovopla@bgumail.bgu.ac.il
}

\begin{abstract}
In a glass house experiment, we investigated the effect of both the frequency of water pulses and the total amount of water supplied on individual performance in the absence and presence of neighbors. We used monocultures and all combinations of pairs of seedlings of three species of perennial grasses, characteristic of different points along a soil moisture gradient within a semi-arid grassland in New Mexico, USA.

In the absence of neighbors, higher total water or more frequent (but smaller) pulses significantly increased growth of all three species. The species with the fastest intrinsic growth rate, and from the most productive habitat, exhibited the largest increase in absolute and relative growth in response to higher total water quantity.

Competitive effects were highly significant overall and there were significant hierarchies of competitive ability. Under frequent pulses, the fast-growing species from the most productive environment was the best competitor in terms of both ability to suppress other plants and ability to tolerate the presence of neighbors. However, under infrequent pulses, the slowest growing species from the least productive environment became a much stronger competitor, again in terms of both suppression and tolerance of neighbors.

While differences in total water availability had greater effects than differences in pulsing regime on individual plant performance in the absence of competition, pulsing regime had much stronger effects on relative competitive abilities and thus may be more likely to influence field distribution patterns.
\end{abstract}

Keywords: Competitive effect; Competitive response; Hilaria jamesii; Pulsing regime; Scleropogon brevifolius; Sporobolus airoides; Temporal heterogeneity.

Nomenclature: Munz (1959).

Abbreviation: $\operatorname{lnRR}=$ natural $\log$ of the response ratio.

\section{Introduction}

Environments typically differ in the degree of spatial and temporal heterogeneity of resource supply, as well as in total resource quantity. A number of studies have examined how individual plants respond to either spatial patchiness in soil resources (Drew \& Saker 1975; Gupta \& Rorison 1975; Crick \& Grime 1987; Caldwell et al. 1991a; Gersani \& Sachs 1992; Caldwell \& Pearcy 1994; Bilbrough \& Caldwell 1995), or, less commonly, temporal pulsing of soil resources (Campbell \& Grime 1989; Miao \& Bazzaz 1990; Jonasson \& Chapin 1991; Bowman 1992; Robinson 1994; Lodge et al. 1994; Bilbrough \& Caldwell 1997). These studies have demonstrated that the patterning of resource supply can be important for the performance of individual plants. However, for resource heterogeneity to also significantly influence community structure, species must respond differentially to this heterogeneity. Such differential responses should then result in different competitive interactions under different resource environments, and therefore in changes in the organization of communities (Campbell \& Grime 1989; Caldwell et al. 1991b). However, almost no experiments to date have directly assessed the influence of resource heterogeneity per se on the outcome of interactions between individual plants (but see Cahill \& Casper 1999).

In this paper, we focus on temporal variation in resources and report results from a glasshouse experiment in which we compared the effects of total resource supply and of the frequency of resource pulses on growth and competitive ability of individual plants. The comparisons were made for three co-occurring species characteristic of different points along a productivity gradient to explore the potential for resource pulsing to influence distribution patterns. We address the following questions that are relevant to understanding the potential impact of pulse regime on species distributions and abundance: Assuming absence of interactions among individuals, we have two questions.

1. Regardless of species, can plant performance be affected by pulse frequency as well as by total resource 
quantity? For nutrient pulses, growth has been found to be better under larger, but less frequent nutrient pulses (Crick \& Grime 1987; Campbell \& Grime 1989; Bilbrough \& Caldwell 1997), but response to water pulses for non-agricultural plants has not been tested.

2. Are species from different points along a natural resource supply gradient differentially affected by pulse frequency and/or total resource quantity? Crick \& Grime (1987) and Campbell \& Grime (1989) have found that fast-growing species from high productivity environments are better able to increase their growth in response to large pulses.

In the presence of interactions among individuals, two other questions are:

3. Regardless of species, is competition intensity affected by pulse frequency and/or total resource quantity? The effect of resource quantity, especially of nutrients, on the magnitude of competition has been extensively explored in both field and greenhouse experiments (review in Goldberg et al. 1999). However, much less is known about effects of water supply on competition intensity (Goldberg \& Novoplansky 1997) and no studies have addressed effects of pulsing of any type of resource. If pulsing regime, as well as magnitude of resources, can influence competition intensity, it may explain some of the variation in results of experiments testing effects of productivity on competitive outcomes (Goldberg \& Novoplansky 1997; Goldberg et al. 1999).

4. Are species' competitive abilities differentially affected by pulse frequency and/or total resource quantity? Specifically, if species differ in their ability to take advantage of small and large pulses in the absence of interactions, are those with the highest increase in growth with a given pulsing regime the best competitors under that regime?

To answer these questions, we conducted a competition experiment under controlled glasshouse conditions in which it was possible to manipulate independently the total quantity of resource and the frequency of resource pulses. We chose this approach because under natural conditions, frequency of pulse events and total resource amount are often positively correlated (NoyMeir 1973; Chapin 1980), making it impossible to disentangle their effects. As test species, we used three grass species that dominate different points along a small-scale soil moisture/standing crop gradient in semiarid grassland and therefore we used water as the critical soil resource. Water was also selected because its pulsing regime could be easily manipulated and because effects of water pulsing may be sharper than nutrient pulsing because water is less easily stored in the tissues of most plants (other than succulents).

\section{Methods}

\section{Species and general experimental design}

The three test species are clonal grasses common in semi-arid grasslands of the southwestern USA. We used plants grown from seeds collected in the Sevilleta $\mathrm{Na}-$ tional Wildlife Refuge in New Mexico, where the three species dominate different habitats along small-scale gradients in soil moisture availability and standing crop within the semi-arid grasslands. The gradient ranges from the floodplains of the dry riverbeds (arroyos) that flood 0-5 times a year after large rain events, to much drier clay swales within the surrounding uplands and covers at least a five-fold range in standing crop. While the three species co-occur throughout the gradient, they switch in relative abundance, with Sporobolus airoides most abundant in the more productive floodplains, Hilaria jamesii most abundant on the surrounding coarsetextured plains with intermediate standing crop, and Scleropogon brevifolius most abundant in clay swales with lowest standing crop (Goldberg \& Novoplansky unpubl.). Sporobolus airoides has a tussock growth form and is by far the largest of the three species with clonal diameter often $>1 \mathrm{~m}$ and height of individual ramets $>0.8 \mathrm{~m}$. Hilaria jamesii has intermediate-size ramets $(10-50 \mathrm{~cm}$ in height) and wide-spreading clones due to its rhizomatous, guerilla growth form. Scleropogon brevifolius has very short ramets $(<10-20 \mathrm{~cm})$ and spreads by stolons with a phalanx growth form. Although Sporobolus airoides is the largest of the three species, it has much smaller seeds than the other two species $(0.2 \mathrm{mg}$ vs. $1.8 \mathrm{mg}$ for Hilaria jamesii and 0.9 $\mathrm{mg}$ for Scleropogon brevifolius).

The experimental design consisted of a four-way factorial competition experiment with three target species by four neighbor treatments (a single target plant grown alone or with one individual of one of the three species) by two water levels (high, low) by two pulse frequencies (frequent, infrequent). Each treatment combination had 15 replicates for a total of 720 pots.

\section{Growth conditions and experimental protocol}

Seeds were sown in soil flats, at high water levels to ensure establishment, in a glasshouse at the Matthaei Botanical Gardens of the University of Michigan in June, 1993. 14 days after sowing, the seedlings were transplanted to $10 \mathrm{~cm}$ diameter and $25 \mathrm{~cm}$ tall pots. The bottom of each pot was filled with $4 \mathrm{~cm}$ of Styrofoam peanuts. The rest of the pot was filled with a $58-42 \%$ mixture of sand and Turface (baked clay particles; Profile Products, Illinois) which represented the average percent sand and clay across the soils dominated by 
these three species in the Sevilleta. Nutrients were provided by a 14:14:14 (N-P-K + micro-elements) slow release fertilizer (Osmocote, Scotts, Ohio) thoroughly mixed into the medium. Natural and supplementary light (daily $12 \mathrm{~h}$ of a mixture of high-pressure sodium and incandescent lamps) summed to an average of 848 mmol m${ }^{-2} \mathrm{~s}^{-1}$ at noon (under clear skies). To ensure survival of most seedlings during the experiment so that growth could be compared, we conducted preliminary experiments to determine the maximum duration of interpulse intervals that all three species could survive (Novoplansky \& Goldberg unpubl.).

Treatments were assigned to pots in a randomized block design. Because light levels were spatially heterogeneous in the glasshouse, we assigned pots to blocks defined by similar light measurements taken at the rim of each pot rather than by spatial location on the benches. Pots within each block were randomly assigned to target, neighbor, water quantity, and pulse frequency treatments. For the first week after transplanting all pots were irrigated with $25 \mathrm{ml}$ of water daily and during the following 63 days the pots were periodically irrigated according to their assigned water regime. The low and the high water treatments received totals of $105 \mathrm{ml}$ and $210 \mathrm{ml}$ of water, respectively over each 21-day period. This amount was divided into seven irrigation events in the frequent pulse treatments and a single event in the infrequent pulse treatments. Pots were therefore irrigated every 3 or 21 days in the frequent and infrequent pulse treatments, respectively. The maximum amount of water at any single irrigation event was chosen so it would not exceed the field capacity of the pots. At harvest, the above-ground parts of every plant were collected. The roots were collected and washed using a metal sieve mesh size 250 . Root systems from different plants in the same pot were carefully separated. Less than $8 \%$ of the total root mass in a pot consisted of unattached roots; this mass was assigned to each of the two plants in a pot based on the proportion of total dry root mass belonging to each of the plants.

\section{Statistical analyses}

To address our first two questions about plant response to water pulse frequency and quantity in the absence of interactions, we compared total mass per plant and allocation to roots among target species in the absence of neighbors and the two water treatments using three-way ANOVAs.

To address our third and fourth questions about how the magnitude of competition changes among species and in response to water pulse frequency and quantity, we first calculated an index of the magnitude of competition by standardizing biomass of target species in the presence of neighbors to biomass in their absences. This made it possible to compare target species or environments that may have quite different growth rates in the absence of competition (Grace 1993, 1995; Goldberg \& Scheiner 1993). As recommended by Hedges et al. (1999) and Goldberg et al. (1999), we used the $\ln$ response ratio (lnRR) for this standardization, where,

$$
\ln R R=\ln \frac{\text { mass of target species } i \text { with neighbor species } j}{\text { mass of species i grown as a single individual }}
$$

Hedges et al. (1999) have explored the statistical properties of the ln response ratio rather thoroughly and shown it has major advantages over other indices of competition intensity. Competitive effects of neighbors are indicated by negative values of $\operatorname{lnRR}$ and facilitative effects by positive values.

We then used a four-way ANOVA to test the main effects and interactions of neighbor species, target species, water pulse frequency, and water quantity on $\ln R R$. This analysis excluded the no-neighbor treatments because $\operatorname{lnRR}$ already takes into account performance in the absence of neighbors. The advantage of this fourway analysis of an index of competition over a five-way analysis of absolute performance with explicit inclusion of competition as a factor in the ANOVA is that we can answer our questions using statistical significance of main effects in the analysis, rather than by less powerful tests of statistical significance of interaction terms. For example, the effect of pulse frequency on competition intensity is tested by the main effect of pulse frequency in the ANOVA of InRR, rather than by a competition $x$ pulse frequency interaction term. Similarly, a significant main effect of target species indicates that species differ in the degree to which they are suppressed by neighbors (competitive response sensu Goldberg \& Werner 1983). Significant neighbor effects indicate that species differ in the degree to which they suppress target plants (competitive effect sensu Goldberg \& Werner 1983). A second advantage of this analytical approach is that it allowed us to simplify the design of the experiment because it only required a single 'no competition' treatment for each target species in each pulse frequency-quantity combination.

A similar four-way ANOVA was used to test effects of the species combinations and environmental treatments on the proportion of total biomass allocated to roots. Because this response variable is already a ratio, we did not standardize to performance in the absence of competition, so this ANOVA compares among different species of neighbor but not whether allocation differs between the presence and absence of any neighbors.

All statistical analyses were conducted using SYSTAT 7.0 (Anon. 1997). 


\section{Results}

Overall survival of seedlings throughout the experiment was quite high $(>85 \%)$ and did not differ significantly among treatments. Therefore we report results only for total biomass and biomass allocation to roots.

\section{Species differences and effects of pulse frequency and} water quantity in the absence of neighbors

Having more frequent (though smaller) pulses or higher total quantity of water significantly increased total mass of individual plants grown without neighbors, for all three target species (Table 1, Fig. 1). In the particular quantitative combination of treatments we used, total water quantity had a larger effect than did the pulse frequency (Fig. 1).

Target species also differed strongly in mass in all environmental treatments, (Table 1), with Sporobolus airoides always larger than Hilaria jamesii, which was always larger than Scleropogon brevifolius (Fig.1). These rankings of seedling size corresponds to the rankings of adult size and of habitat productivity. The species also differed strongly in their response to the water treatments, although not to the pulse frequency treatments (water $\times$ target and pulse $\times$ target interactions, respectively, in Table 1). The order of responsiveness to the water treatments also follows the order of habitat productivity, with Sporobolus airoides, from the most productive habitat, showing the greatest increases in total and shoot biomass (both in absolute and proportional terms) in higher compared with lower water treatments (Fig. 1).

\section{Competition intensity and competitive hierarchies}

Mean mass of target plants was smaller in the presence of neighbors, regardless of species, relative to the absence of neighbors for every species and environment treatment combination (indicated by negative values of mean lnRR in Fig. 2).

Overall, the identity of interacting species had much more significant impacts on the magnitude of competition than did the environment (Table 2). In addition, any effects of the pulse frequency and, to a lesser extent, the water quantity treatments significantly depended on neighbor and target identity (Table 2), so that there were no consistent effects of the environmental treatments on competition intensity (Fig. 2).

The three neighbor species differed significantly in their ability to suppress other plants overall, although the hierarchies depended on pulse frequency, and, to a lesser extent on total water (Table 2). In the frequent pulse treatments, regardless of total water quantity, the
Table 1. Results of ANOVAs for the effect of water treatment $(W)$, pulse treatment $(P)$, and target species $(T)$ on total biomass, and biomass allocation to roots of plants grown with no neighbors. Treatment means are shown in Fig. 1.

$* * *=P<0.001, * *=P<0.01, *=P<0.05$, n.s. $=P>0.05$.

\begin{tabular}{lccccc}
\hline $\begin{array}{l}\text { Dependent } \\
\text { variable }\end{array}$ & Df & \multicolumn{2}{c}{ Total mass } & \multicolumn{3}{c}{ Proportion of root } \\
& & MS & Sign. & MS & Sign. \\
\hline Water & 1 & 11.112 & $* * *$ & 0.038 & $*$ \\
Pulse & 1 & 2.544 & $* * *$ & 0.020 & n.s. \\
Target & 2 & 4.565 & $* * *$ & 0.370 & $* * *$ \\
$\mathrm{~W} \times \mathrm{P}$ & 1 & 0.309 & $*$ & 0.003 & n.s. \\
$\mathrm{W} \times \mathrm{T}$ & 2 & 0.615 & $* * *$ & 0.004 & n.s. \\
$\mathrm{P} \times \mathrm{T}$ & 2 & 0.085 & n.s. & 0.016 & n.s. \\
$\mathrm{W} \times \mathrm{P} \times \mathrm{T}$ & 2 & 0.121 & n.s. & 0.011 & n.s. \\
Error & 168 & 0.072 & & 0.007 & \\
\hline
\end{tabular}

hierarchy of neighbor effects was consistently Sporobolus airoides $\geq$ Hilaria jamesii $\geq$ Scleropogon brevifolius (Fig. 2). This ranking follows that of individual seedling mass in the absence of competition in all environments (Fig. 1). However, in the less productive infrequent pulse treatments, especially at low total water, the two larger species tended to become much weaker effect competitors (i.e., reduced target growth much less). The competitive ability of the smallest species, Scleropogon brevifolius, was usually less affected by the pulsing treatments, so that it actually became the strongest or almost strongest competitor in the least productive environment. Thus, despite the stronger effects of the total water treatment than the pulse treatment on growth in
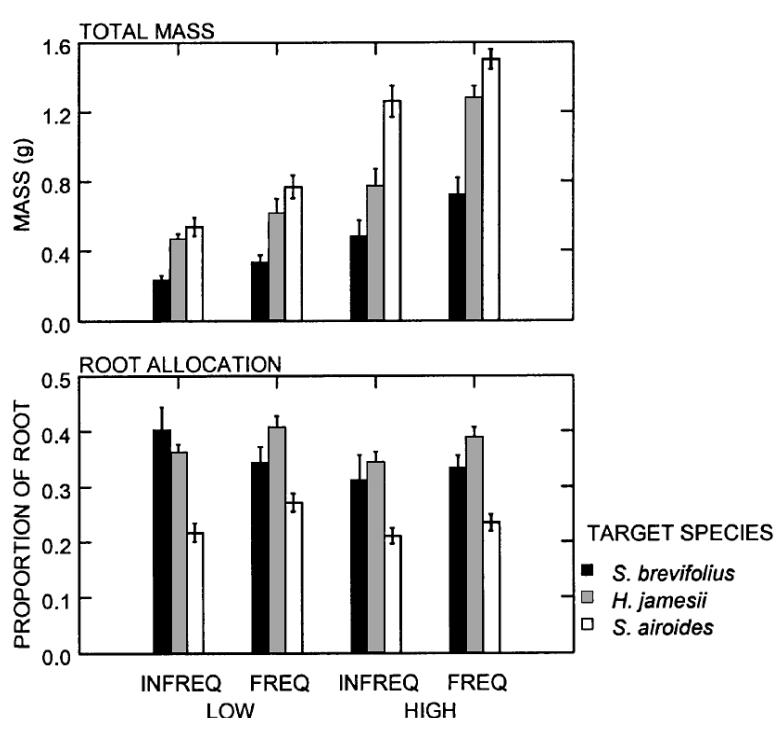

Fig. 1. Effect of total water quantity (high and low) and pulsing frequency on total biomass and allocation to roots of individual target plants of three species in the absence of interactions. Values are means \pm S.E. 


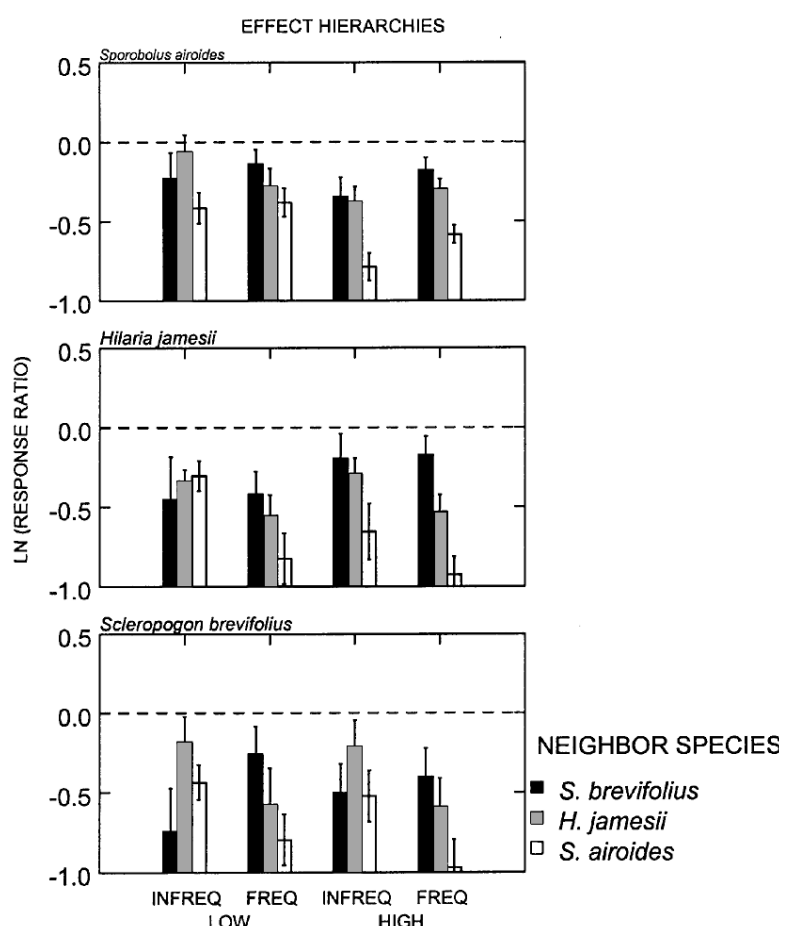

Fig. 2. Effect of water quantity and pulsing frequency on competitive effect hierarchies. Each of the panels contains data for a single target species and compares the competition intensity due to each of the neighbor species under each of the four environmental treatment combinations. Competition intensity is measured as the natural $\log$ of the ratio of total biomass of a target individual grown with a given neighbor species relative to that with no neighbors $(=\ln R R)$. Values are means $\pm \mathrm{S}$.E. The dashed line represents a response ratio of 1 ( $\ln R R=0$ ), i.e., no effect of neighbors; negative values indicate competition and positive values indicate facilitation.

the absence of neighbors (Fig. 1), the pulse frequency treatment had a stronger effect on the competitive effect hierarchies (Fig. 2). Target species also differed significantly in their ability to tolerate or avoid suppression by neighbors, and, again, hierarchies depended on the pulse treatments, although, in this case, not even weakly on total water treatment (Table 2). However, unlike the effect hierarchies which were largely similar for all three target species, the response hierarchies among the target species appeared to depend on whether the target plants were growing with the two larger neighbor species or with the smallest neighbor species (Fig. 3). For targets growing with the two larger neighbor species (top two panels in Fig. 3), the response hierarchies were largely similar to the effect hierarchies: in the more productive frequent pulse treatments, Sporobolus airoides was the best competitor, while in the less productive infrequent pulse treatments, Scleropogon brevifolius became a relatively better response competitor, i.e. was less
Table 2. Results of ANOVAs for the effects of water treatment $(W)$, pulse treatment $(P)$, target species $(T)$, and neighbor species $(N)$ on competitive intensity and on biomass allocation to roots of the target plants. Competition intensity is measured by the $\ln$ response ratio $(\ln R R)$ or the natural $\log$ of the ratio of total target biomass with neighbors present relative to biomass in the absence of any neighbor individuals.

$* * *=P<0.001$, ** $=P<0.01, *=P<0.05$, n.s. $=P>0.05$.

\begin{tabular}{lrrrrr}
\hline $\begin{array}{l}\text { Dependent } \\
\text { variable }\end{array}$ & df & \multicolumn{2}{c}{$\begin{array}{c}\text { Total mass } \\
\text { (as ln } R R)\end{array}$} & \multicolumn{2}{c}{ Proportion of root } \\
& & MS & Sign. & MS & Sign. \\
\hline Water & 1 & 0.461 & n.s. & $<0.001$ & n.s. \\
Pulse & 1 & 1.095 & $*$ & 0.061 & n.s. \\
Target & 2 & 1.214 & $* *$ & 1.803 & $* * *$ \\
Neighbor & 2 & 3.973 & $* * *$ & 0.447 & $* * *$ \\
$\mathrm{~W} \times \mathrm{P}$ & 1 & 0.035 & n.s. & 0.001 & n.s. \\
$\mathrm{W} \times \mathrm{T}$ & 2 & 0.350 & n.s. & 0.024 & n.s. \\
$\mathrm{W} \times \mathrm{N}$ & 2 & 0.754 & $*$ & 0.022 & n.s. \\
$\mathrm{P} \times \mathrm{T}$ & 2 & 0.750 & $*$ & 0.001 & n.s. \\
$\mathrm{P} \times \mathrm{N}$ & 2 & 1.575 & $* *$ & 0.012 & n.s. \\
$\mathrm{T} \times \mathrm{N}$ & 4 & 0.132 & n.s. & 0.069 & $*$ \\
$\mathrm{~W} \times \mathrm{P} \times \mathrm{T}$ & 2 & 0.231 & n.s. & 0.016 & n.s. \\
$\mathrm{W} \times \mathrm{P} \times \mathrm{N}$ & 2 & 0.132 & n.s. & 0.027 & n.s. \\
$\mathrm{P} \times \mathrm{T} \times \mathrm{N}$ & 4 & 0.423 & n.s. & 0.011 & n.s. \\
$\mathrm{W} \times \mathrm{P} \times \mathrm{T} \times \mathrm{N}$ & 4 & 0.054 & n.s. & 0.008 & n.s. \\
Error & 402 & 0.238 & & 0.021 & \\
\hline
\end{tabular}

suppressed by neighbors. These shifts in relative competitive ability from the frequent pulse treatments resulted in a complete reversal of competitive response hierarchies in the infrequent pulse at high total water. For target plants growing with the smallest neighbor species, Scleropogon brevifolius, Scleropogon targets appeared to be the most suppressed, even in the infrequent pulse environments. Thus, intraspecific competition was especially strong for Scleropogon.

\section{Root allocation}

In the absence of neighbors, relative biomass allocation to roots was significantly decreased overall by higher total water although the effects were much weaker than on absolute size (Table 1, solid bars in Fig. 4). In contrast, pulse frequency had no significant effect on root allocation, despite its large effect on absolute size. Target species differed strongly in root allocation (Table 1), with the highest allocation to roots by Hilaria jamesii and Scleropogon brevifolius (30-41\%), while Sporobolus airoides, from the most productive habitat, always had the lowest allocation (21-27\%; Fig. 4).

In the presence of neighbors, the environmental treatments had no effect at all on root allocation (Table 2). Although the basic allocation differences among targets found in the absence of neighbors remained, the neighbor species caused some differences as well (Table 2). In general, Scleropogon brevifolius neighbors tended to 


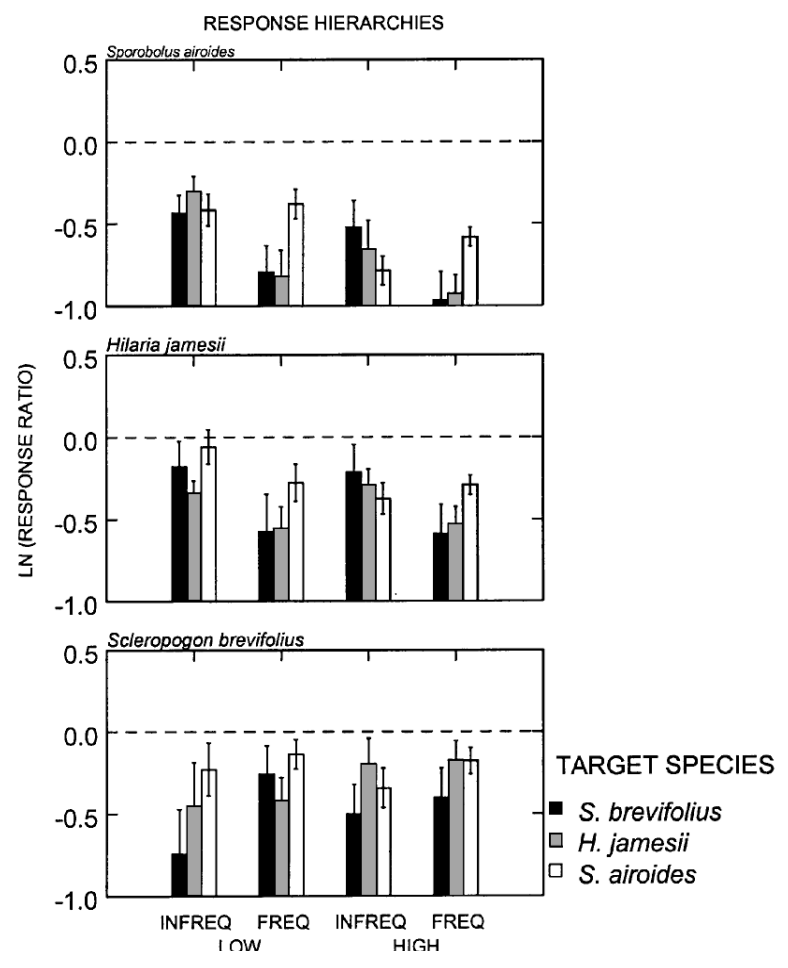

Fig. 3. Effect of water quantity and pulsing frequency on competitive response hierarchies. Each of the panels contains data for a single neighbor species and compares the competition intensity experienced by each of the target species under each of the four environmental treatment combinations. Competition intensity is measured as the natural $\log$ of the ratio of total biomass of a target individual grown with a given neighbor species relative to that with no neighbors $(=\ln R R)$. Values are means \pm S.E. The dashed line represents a response ratio of 1 ( $\ln R R=0$ ), i.e., no effect of neighbors; negative values indicate competition and positive values indicate facilitation.

cause a decrease or no change in allocation to roots by targets (except for intraspecific competition), while Hilaria jamesii and Sporobolus airoides neighbors tended to cause an increase or no change in root allocation (Fig. 4). The latter pattern was much the strongest for Scleropogon brevifolius targets (Fig. 4).

\section{Discussion}

The influence of temporal heterogeneity of supply has lately begun to receive a lot of attention. To date, almost all of this research has focused on the role of mineral nutrient pulses for the performance of single plants. This study on a pulsing regime was a first attempt to incorporate two important, but neglected, aspects of the dynamics of resource supply: the effect of

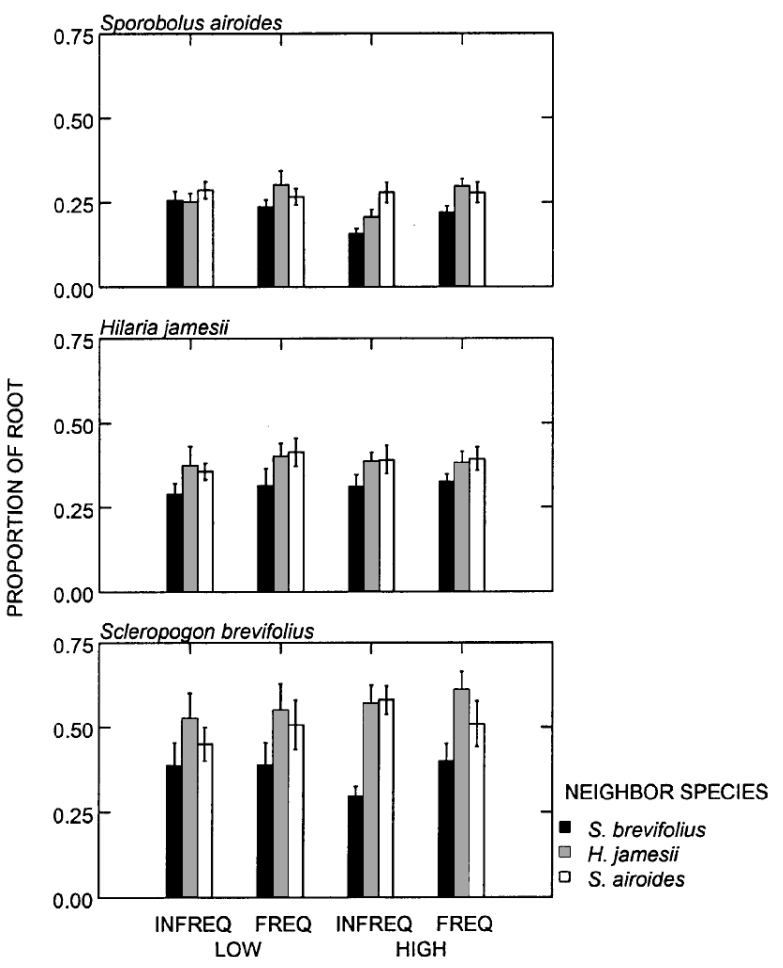

Fig. 4. Effect of different species of neighbors on the proportion of biomass allocated to roots of the three target species grown under various environmental treatments. Values are means \pm S.E.

water, rather than mineral nutrient pulses, and the effect on interacting, rather than just isolated, plants. The short growth period and relatively small glasshouse containers limit quantitative extrapolation of these results to field conditions. Nevertheless, our observations of strong effects of pulsing regime on individual plant performance and on competitive hierarchies indicate the potential importance of the patterns of resource dynamics as well as mean resource levels under field conditions and suggest that field experiments manipulating both pulsing regime and competitive interactions are highly warranted.

Effects of pulse frequency and total resource quantity on plant performance in the absence of interactions

Both total water quantity and pulse frequency had highly significant influences on the performance of the three target species in the absence of neighbors, with more water or smaller, but more frequent pulses, leading to higher growth rates. If similar results were to be found under field conditions, one important consequence could be that even very small (but frequent) precipitation events in semi-arid and arid regions might not only 
be ecologically significant in the sense that plants can use them (Sala \& Lauenroth 1982), but also be more effective than fewer but bigger rains of the same cumulative magnitude, compensating for low overall precipitation levels. These results suggest that patterns of rainfall could directly impact on productivity as well; further exploration of this possibility in field experiments and with wider ranges of combinations of frequency and total amount would be valuable. In practical terms, our results are consistent with the results from agricultural experiments (e.g. Komamura \& Yamamoto 1989; Chu et al. 1995; Sepaskhah \& Kamgar-Haghighi 1997; Saeed \& El-Nadi 1998).

These results contrast with those found in the few cases where plant performance has been compared under different nutrient pulsing regimes: performance tends to be better under larger, less frequent nutrient pulses (Crick \& Grime 1987; Campbell \& Grime 1989; Bilbrough \& Caldwell 1997). However, because so few studies have been conducted, this difference may be simply related to the particular size and frequency of pulses chosen for studies of nutrients, and, in our case, water. Nevertheless, the pattern to date suggests that more direct comparisons of responses to water and nutrient pulsing regimes would be useful in understanding response of plants to resource dynamics.

Differences among species in response to pulse frequency and quantity in the absence of interactions

The target species differed strongly in their response to total water, with the magnitude of absolute and proportional growth response increasing with increasing maximum plant size and growth rate of these three species (Fig. 1). This corresponds with the increasing productivity and standing crop of the typical habitats of these species and is consistent with numerous studies of herbaceous plants, although most of these have been concerned with responses to supplemental nutrients rather than water (Grime 1979; Shipley \& Keddy 1988; Lambers \& Poorter 1992).

In contrast, in the absence of competition, the target species did not differ in response to pulse frequency, even though studies on response to nutrients suggest strong responses to pulsing. Glasshouse experiments with mineral pulsing have suggested a trade-off between 'scale' and 'precision' of resource acquisition (Campbell et al. 1991; Grime 1994). According to this theory, fast-growing competitive dominants are expected to efficiently take advantage of large (high in level and long in time) resource pulses by rapid plastic growth of relatively short-lived roots while slow-growing stress tolerators are expected to develop in a more conservative way, allocating a greater proportion of their biomass to long-living roots that are capable of capturing small and ephemeral pulses of the limiting resource (Crick \& Grime 1987; Campbell \& Grime 1989; Grime 1994).

\section{Effects of pulse frequency and total resource quantity on the overall magnitude of competition}

Effects of higher productivity on competition intensity have been a controversial topic, with different models predicting higher intensity (Grime 1973; Keddy 1989) and constant intensity (Newman 1973; Tilman 1988). In this greenhouse experiment, we could not detect any clear patterns with respect to productivity, even though there was a statistically significant effect of pulse frequency on competition intensity. Thus, results appear to be consistent with the Newman-Tilman hypothesis of competition intensity independent of productivity, but a hint remains that further exploration of pulsing effects on competition intensity would be valuable. Results from field experiments on effects of productivity on competition intensity are highly variable among studies (reviews in Goldberg \& Barton 1992; Kadmon 1995; Twolan-Strutt \& Keddy 1996; Goldberg et al. 1999) and it remains possible that patterns in temporal (and, likely, spatial) heterogeneity may explain some of this variation in results.

\section{Effect of pulse frequency and total resource quantity on competitive hierarchies}

Consistency of competitive hierarchies between environments is an important distinction between alternative models of community structure (Grime 1977 vs. Tilman 1988, 1990). If species' positions within competitive hierarchies switch between environments, competition has strong potential to be an important process determining differences in species composition across environmental gradients.

We found that both the effect and response hierarchies differed consistently between frequent and infrequent pulses, while the total amount of water had relatively little effect on the competitive hierarchies. Thus, our data suggest that, at least under the conditions chosen for our experiment, the degree of temporal heterogeneity in water supply has more potential to influence patterns of plant distribution than the mean amount of water availability. If temporal heterogeneity of resource supply is indeed an important factor controlling competitive hierarchies more generally, it suggests that existing data may underestimate the degree of hierarchy change between environments because most greenhouse and field experiments have only manipulated mean resource supply. 
The potential effect of the hierarchy switches on distribution patterns is well illustrated by our three test species. Under frequent pulses, regardless of total water quantity, the effect and response hierarchies were quite similar: the largest, fastest growing species from the most productive habitat (Sporobolus airoides) was the best competitor and the smallest, slowest growing species from the least productive habitat (Scleropogon brevifolius) was the poorest competitor, both in terms of suppressing other plants (effect) and not being suppressed itself (response). This general hierarchy is consistent with both Tilman's (1988) and Grime's (1977) predictions that plant size and growth rate are key traits determining competitive ability in short-term interactions among individuals, regardless of productivity.

However, under the less productive infrequent pulses, the hierarchies shift such that the smallest species from the least productive environment, Scleropogon brevifolius, becomes a relatively stronger competitor compared to the other two larger species, sometimes even completely reversing the competitive hierarchy found in the frequent pulse treatments. The mechanism underlying this shift is not clear. For example, Scleropogon seems to be less responsive to variation in water level in the absence of competition (Fig.1) and this tolerance in turn is perhaps due to its greater allocation to roots (Fig. 4). However, resource competition theory would predict this to lead to greater competitive ability (at least in terms of response; Goldberg 1990) in low water quantity even more than in infrequent pulses, because in our experimental design, less frequent pulses also meant that each pulse was larger. This was not the case; the target hierarchy did not change at all with total water quantity. Thus, the greater shift in competitive hierarchy between environments with different resource dynamics than with different mean resource levels implies that some quite different mechanism may be at work. For example, one highly speculative explanation of the stronger competitive ability of Scleropogon under infrequent pulses is an allelopathic effect of its roots that is diluted and masked by the frequent water inputs in the frequent pulse treatments.

Our finding of a shift in hierarchy between different temporal patterns of resource supply contrasts with the only other study of which we are aware that tests effects of resource heterogeneity on interspecific competition. Cahill \& Casper (1999) manipulated spatial heterogeneity of nutrient supply and found no shift in competitive hierarchies; while both competing species they studied showed strong responses to heterogeneity, their responses were similar. Further study is needed to illuminate the possible qualitative differences between spatial and temporal heterogeneity and the scales at which they might influence community-level phenomena in various environments.

\section{Conclusions}

Our results emphasize the importance of two distinctions that have not yet received much explicit attention in plant ecological studies. First is the distinction between mean resource levels and the temporal dynamics of resources, i.e. temporal heterogeneity in resource supply. Our results suggests that it may now be useful to shift the focus of experimental work from understanding responses to mean resource conditions to the more complicated question of understanding how resource dynamics influence patterns of species interactions and community structure.

Second, much of the basic theory in plant community ecology has tended to combine nutrients and water as 'below-ground resources' or focused almost exclusively on only one of these resource types (Grime 1977; Tilman 1988; Smith \& Huston 1989; Goldberg 1990). However, our results for effects of water pulses differ from those of most experimental work on nutrient pulses. For further development of general theory, it is critical that we better understand the extent to which 'belowground resources' can be lumped together or whether water and nutrients, or indeed different mineral nutrients, must be treated separately.

Acknowledgements. We thank the dedicated support of the staff of the Matthaei Botanical Gardens of the University of Michigan for assistance in conducting the experiment and Andy Dyer, Katie Nash Suding, Paul Foster, Jill Rapson, and several anonymous reviewers for helpful comments on the manuscript. The study was supported by the National Science Foundation grant BSR 9007977 and a grant from the Office of the Vice-President of the University of Michigan.

\section{References}

Anon. 1997. SYSTAT for Windows Version 7.01. SPSS, Inc, Chicago, IL.

Bilbrough, C.J. \& Caldwell, M.M. 1995. The effect of shading and $\mathrm{N}$ status on root proliferation in nutrient patches by the perennial grass Agropyron desertorum in the field. Oecologia (Berl.) 103: 10-16.

Bilbrough, C.J. \& Caldwell, M.M. 1997. Exploitation of springtime ephemeral $\mathrm{N}$ pulses by six Great Basin plant species. Ecology 78: 231-243.

Bowman, W.D. 1992. Inputs and storage of nitrogen in winter snowpack in an alpine ecosystem. Arct. Alp. Res. 24: 211215.

Cahill, J.F. Jr. \& Casper, B.B. 1999. Growth consequences of soil nutrient heterogeneity for two old-field herbs, Ambrosia artemisiifolia and Phytolacaa americana, grown individually and in combination. Ann. Bot. 83: 471-478.

Caldwell, M.M. \& Pearcy, R.W. 1994. Exploitation of environmental heterogeneity by plants. Academic Press, San 
Diego, CA.

Caldwell, M.M., Manwaring, J.H. \& Durham, S.L. 1991a. The microscale distribution of neighboring plant roots in fertile soil microsites. Funct. Ecol. 5: 765-772.

Caldwell, M.M., Manwaring, J.H. \& Jackson, R.B. 1991b. Exploitation of phosphate from fertile soil microsites by three Great Basin perennials when in competition. Funct. Ecol. 5: 757-764.

Campbell, B.D. \& Grime, J.P. 1989. A comparative study of plant responsiveness to the duration of episodes of mineral nutrient enrichment. New Phytol. 112: 261-267.

Campbell, B.D., Grime, J.P. \& Mackey, J.M.L. 1991. A tradeoff between scale and precision in resource foraging. Oecologia (Berl.) 87: 532-538.

Chapin, F.S. III. 1980. The mineral nutrition of wild plants. Annu. Rev. Ecol. Syst. 11: 233-260.

Chu, C.C., Henneberry, T.J. \& Radin, J.W. 1995. Effect of irrigation frequency on cotton yield in short-season production systems. Crop Sci. 35: 1069-1073.

Crick, J.C. \& Grime, J.P. 1987. Morphological plasticity and mineral nutrient capture in two herbaceous species of contrasted ecology. New Phytol. 107: 403-414.

Drew, M.C. \& Saker, L.R. 1975. Nutrient supply and the growth of seminal root system in barley. II. Localized compensatory increase in lateral root growth and rates of nitrate uptake when nitrate supply is restricted to only part of the root system. J. Exp. Bot. 26: 79-90.

Gersani, M. \& Sachs, T. 1992. Developmental correlations between roots in heterogeneous environments. Plant Cell Environ. 15: 463-469.

Goldberg, D.E. 1990. Components of resource competition in plant communities. In: Grace, J.B. \& Tilman, D. (eds.) Perspectives on plant competition, pp. 27-49. Academic Press, New York, NY.

Goldberg, D.E. \& Barton, A.M. 1992. Patterns and consequences of interspecific competition in natural communities: a review of field experiments with plants. Am. Nat. 139: 771-801.

Goldberg, D.E. \& Novoplansky, A. 1997. On the relative importance of competition in unproductive environments. J. Ecol. 85: 409-418.

Goldberg, D.E. \& Scheiner, S.M. 1993. ANOVA and ANCOVA: field competition experiments. In: Scheiner, S. \& Gurevitch, J. (eds.) Design and analysis of ecological experiments, pp. 69-93. Chapman and Hall, New York, NY.

Goldberg, D.E. \& Werner, P. 1983. Equivalence of competitors in plant communities: a null hypothesis and a field approach. Am. J. Bot. 70: 1098-1104.

Goldberg, D.E., Rajaniemi, T., Gurevitch, J. \& Stewart-Oaten, A. 1999. Empirical approaches to quantifying interaction intensity: competition and facilitation along productivity gradients. Ecology 80: 1118-1131.

Grace, J.B. 1993. The effects of habitat productivity on competitive intensity. Trends Ecol. Evol. 8: 229-230.

Grace, J.B. 1995. On the measurement of plant competition intensity. Ecology 76: 305-308.

Gupta, P.L. \& Rorison, I.H. 1975. Seasonal differences in the availability of nutrients down a podzolic profile. J. Ecol.
63: $521-534$.

Grime, J.P. 1973. Competitive exclusion in herbaceous vegetation. Nature (Lond.) 242: 344-347.

Grime, J.P. 1977. Evidence for the existence of three primary strategies in plants and its relevance to ecological and evolutionary theory. Am. Nat. 111: 1169-1194.

Grime, J.P. 1979. Plant strategies and vegetation processes. John Wiley and Sons, Chichester.

Grime, J.P. 1994. The role of plasticity in exploiting environmental heterogeneity. In: Caldwell, M.M. \& Pearcy, R.W. (eds.) Exploitation of environmental heterogeneity by plants, pp. 285-304. Academic Press, San Diego, CA.

Hedges, L.V., Gurevitch, J. \& Curtis, P. 1999. The metaanalysis of response ratios in experimental ecology. Ecology 80: 1150-1156.

Jonasson, S. \& Chapin III, F.S. 1991. Seasonal uptake and allocation of phosphorus in Eriophorum vaginatum L. measured by labeling with ${ }^{32}$ P. New Phytol. 118: 349-357.

Kadmon, R. 1995. Plant competition along soil moisture gradients: a field experiment with the desert annual, Stipa capensis. J. Ecol. 83: 253-262.

Keddy, P.A. 1989. Competition. Chapman \& Hall, London.

Komamura, M. \& Yamamoto, T. 1989. Consumptive use of water and water quantity per irrigation after rainfall: fundamental studies on irrigation scheduling for drip irrigation methods: I. Trans. Jpn. Soc. Irrig. Drain. Reclam. Engin. 142: 43-48.

Lambers, H. \& Poorter, H. 1992. Inherent variation in growth rate between higher plants: a search for physiological causes and ecological consequences. Adv. Ecol. Res. 23: 187-261.

Lodge, D.J., McDowell, W.H. \& McSwiney, C.P. 1994. The importance of nutrient pulses in tropical forests. Trends Ecol. Evol. 9: 384-387.

Miao, S.L. \& Bazzaz, F.A. 1990. Responses to nutrient pulses of two colonizers requiring different disturbance frequencies. Ecology 71: 2166-2178.

Munz, P.A. 1959. A California Flora. University of California Press, Berkeley, CA.

Newman, E.I. 1973. Competition and diversity in herbaceous vegetation. Nature (Lond.) 244: 310

Robinson, D. 1994. The responses of plants to non-uniform supplies of nutrients. New Phytol. 127: 635-674.

Noy-Meir, I. 1973. Desert ecosystems: environment and producers. Annu. Rev. Ecol. Syst. 4: 25-51.

Saeed, I.A.M. \& El-Nadi, A.H. 1998. Forage sorghum yield and water use efficiency under variable irrigation. Irrig. Sci. 18: 67-71.

Sala, O.E. \& Lauenroth, W.K. 1982. Small rainfall events: an ecological role in semiarid regions. Oecologia (Berl.) 53: 301-304.

Sepaskhah, A.R. \& Kamgar-Haghighi, A.A. 1997. Water use yield of sugarbeet grown under every-other-furrow irrigation with different irrigation intervals. Agric. Water Manage. 34: 71-79.

Shipley, B. \& Keddy, P.A. 1988. The relationship between relative growth rate and sensitivity to nutrient stress in twenty-eight species of emergent macrophytes. J. Ecol. 76: 1101-1110. 
Smith, T. \& Huston, M. 1989. A theory of the spatial and temporal dynamics of plant communities. Vegetatio 83 : 49-70.

Tilman, D. 1988. Plant strategies and the dynamics and structure of plant communities. Princeton University Press, Princeton, NJ.

Tilman, D. 1990. Mechanisms of plant competition for nutrients: the elements of predictive theory of competition. In: Grace, J.B. \& Tilman, D. (eds.) Perspectives on plant competition, pp. 27-49. Academic Press, New York, NY.
Twolan-Strutt, L. \& Keddy, P.A. 1996. Above and belowground competition intensity in two contrasting wetland plant communities. Ecology 77: 259-270.

Received 5 August 1999;

Revision received 3 August 2000; Final revision received 10 September 2000;

Accepted 26 October 2000.

Coordinating Editor: G. Rapson. 